\title{
Potential impact of flooding on schistosomiasis in Poyang Lake regions based on multi-source remote sensing images
}

Jing-Bo Xue 1,2,3,4,5, Xin-Yi Wang 1,2,3,4,5, Li-Juan Zhang 1,2,3,4,5, Yu-Wan Hao 1,2,3,4,5, Zhe Chen ${ }^{6,7}$, Dan-Dan Lin ${ }^{6,7}$, Jing $X u^{1,2,3,4,5}$, Shang $X_{i a}^{1,2,3,4,5^{*}+}$ and Shi-Zhu Li, $i^{1,2,3,4,5^{*+}}$

\begin{abstract}
Background: Flooding is considered to be one of the most important factors contributing to the rebound of Oncomelania hupensis, a small tropical freshwater snail and the only intermediate host of Schistosoma japonicum, in endemic foci. The aim of this study was to assess the risk of intestinal schistosomiasis transmission impacted by flooding in the region around Poyang Lake using multi-source remote sensing images.
\end{abstract}

Methods: Normalized Difference Vegetation Index (NDVI) data collected by the Landsat 8 satellite were used as an ecological and geographical suitability indicator of $O$. hupensis habitats in the Poyang Lake region. The expansion of the water body due to flooding was estimated using dual-polarized threshold calculations based on dual-polarized synthetic aperture radar (SAR). The image data were captured from the Sentinel-1B satellite in May 2020 before the flood and in July 2020 during the flood. A spatial database of the distribution of snail habitats was created using the 2016 snail survey in Jiangxi Province. The potential spread of O. hupensis snails after the flood was predicted by an overlay analysis of the NDVI maps in the flood-affected areas around Poyang Lake. The risk of schistosomiasis transmission was classified based on $O$. hupensis snail density data and the related NDVI.

Results: The surface area of Poyang Lake was approximately $2207 \mathrm{~km}^{2}$ in May 2020 before the flood and $4403 \mathrm{~km}^{2}$ in July 2020 during the period of peak flooding; this was estimated to be a $99.5 \%$ expansion of the water body due to flooding. After the flood, potential snail habitats were predicted to be concentrated in areas neighboring existing habitats in the marshlands of Poyang Lake. The areas with high risk of schistosomiasis transmission were predicted to be mainly distributed in Yongxiu, Xinjian, Yugan and Poyang (District) along the shores of Poyang Lake. By comparing the predictive results and actual snail distribution, we estimated the predictive accuracy of the model to be $87 \%$, which meant the $87 \%$ of actual snail distribution was correctly identified as snail habitats in the model predictions.

Conclusions: Data on water body expansion due to flooding and environmental factors pertaining to snail breeding may be rapidly extracted from Landsat 8 and Sentinel-1B remote sensing images. Applying multi-source remote sensing data for the timely and effective assessment of potential schistosomiasis transmission risk caused by snail spread during flooding is feasible and will be of great significance for more precision control of schistosomiasis.

Keywords: Schistosomiasis, Flood disaster, Remote sensing, Water extraction

\footnotetext{
*Correspondence: sxia@nipd.chinacdc.cn; lisz@chinacdc.cn

'Shang Xia and Shi-Zhu Li contributed equally to this work

${ }^{1}$ National Institute of Parasitic Diseases, Chinese Center for Diseases

Control and Prevention, Chinese Center for Tropical Diseases Research,

Shanghai 200025, People's Republic of China

Full list of author information is available at the end of the article
}

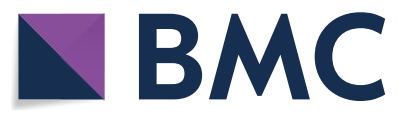

(c) The Author(s) 2021. This article is licensed under a Creative Commons Attribution 4.0 International License, which permits use, sharing, adaptation, distribution and reproduction in any medium or format, as long as you give appropriate credit to the original author(s) and the source, provide a link to the Creative Commons licence, and indicate if changes were made. The images or other third party material in this article are included in the article's Creative Commons licence, unless indicated otherwise in a credit line to the material. If material is not included in the article's Creative Commons licence and your intended use is not permitted by statutory regulation or exceeds the permitted use, you will need to obtain permission directly from the copyright holder. To view a copy of this licence, visit http://creativeco mmons.org/licenses/by/4.0/. The Creative Commons Public Domain Dedication waiver (http://creativecommons.org/publicdomain/ zero/1.0/) applies to the data made available in this article, unless otherwise stated in a credit line to the data. 


\section{Background}

Intestinal schistosomiasis, caused by infection with Schistosoma japonicum, is a zoonotic parasitic disease [1]. In China, schistosomiasis is mainly concentrated along the south of the Yangtze River basin, where it has a substantial impact on human health and socioeconomic development [2, 3]. Oncomelania hupensis, a small tropical freshwater snail, is an amphibious species, and water is one of the essential conditions for its growth and reproduction; these snails will not thrive in persistently dry areas. Young snails live in the water, and mature snails generally live on wet and food-rich land. Regions where the water level varies significantly are suitable for snail breeding if the water flow is slow or the vegetation grows well. Variations in water level greatly affect the reproduction and growth of snails $[4,5]$.

Oncomelania hupensis is the only intermediate host of S. japonicum. [6]. Studies have shown that the geographical distribution of schistosomiasis is strongly associated with the distribution of O. hupensis [3]. The primary distribution of $O$. hupensis along the river system means that it plays a critical role in the transmission of schistosomiasis. In China, O. hupensis is predominantly distributed in marshland and lake areas along the middle and lower reaches of the Yangtze River in the provinces of Hunan, Hubei, Jiangxi, Anhui and Jiangsu. This area covers a landmass of 3.484 to 3.611 thousand $\mathrm{km}^{2}$ and accounts for a geographic distribution of 97.32-98.9\% of snail habitats in China [7].

China began programs to eliminate schistosomiasis in 2016, and since then disease endemicity has been maintained at a historically low level in the country, with the exception of regions with extensive snail habitats [8]. Regular seasonal fluctuations in the water level of Poyang Lake create favorable conditions for snail breeding in the marshlands around this lake. Flooding in the area in 2017 contributed to the expansion of snail habitats along Poyang Lake $[5,9,10]$ by 490 thousand $\mathrm{km}^{2}$, accounting for $98 \%$ of newly detected and re-emerging snail habitats in Jiangxi Province [11]. Additionally, infected bovines maintain a reservoir of schistosomiasis infection in the Poyang Lake region, acting as a source of onward transmission [12]. Recently, regions of schistosomiasis transmission have been identified by wild feces surveillance [13], detection of infected snails by loop-mediated isothermal amplification (LAMP) $[14,15]$ and sentinel mice-base surveillance [16].

Since June 2020, continuous heavy rainfall along the middle and lower reaches of the Yangtze River has resulted in severe flood disasters along the Yangtze River basin and in the areas around Poyang Lake. The highest recorded water level exceeded that of previous record highs following flooding in 1998, and has led to the collapse of dikes and/or waterlogging in many urban areas in China. Control of schistosomiasis in flood-affected areas has been impacted by increased contact with infested water during the fight against floods and the increased spreading of snails attributable to flooding. In this context, the aim of this study was to predict the expansion of $O$. hupensis snail habitats impacted by flooding and to assess the associated potential risk of schistosomiasis transmission in the areas around Poyang Lake using multi-source remote sensing image data and Sentinel-1B satellite radar images.

\section{Methods \\ Study area}

Poyang Lake, the largest freshwater lake in China, is located in the middle and lower reaches of the Yangtze River in the north of Jiangxi Province $\left(28^{\circ} 22^{\prime}-29^{\circ} 45^{\prime} \mathrm{N}, 115^{\circ} 47^{\prime}-116^{\circ} 45^{\prime} \mathrm{E}\right)$. The ecological and geographical features of Poyang Lake are suitable for snail breeding. The lake is fed by water from inland rivers between April and June and by the Yangtze River between July and September, which enables a high water level to be maintained during the spring and summer seasons. A total of 13 counties (cities, districts) in the areas around Poyang Lake are endemic for schistosomiasis, including Nanchang, Xinjian, Jinxian, the hightech zone of Nanchang City, Yongxiu, Gongqingcheng, Lushan, Lianxi, Hukou, Duchang, Poyang, Yugan and Wannian (Fig. 1).

\section{Snail distribution}

Data on snail distribution were obtained from a snail survey carried out in Jiangxi Province in 2016 [11]. The geographical and environmental characteristics of snail distribution were extracted for the 13 counties (cites, districts) in which schistosomiasis is endemic, and the spatial database of snail distribution in the Poyang Lake area was created accordingly. In this study, a $75 \%$ subset of the snail distribution data was randomly selected as a model training dataset, and the remaining $25 \%$ of the data was assigned as the model validation dataset.

\section{Multi-source remote sensing images}

Remote sensing image data collected by the Landsat 8 satellite, with a spatial resolution of $30 \mathrm{~m}$ following geometric correction, convolution interpolation and resampling, were extracted from the NASA EarthData database (https://earthdata.nasa.gov/). Operational Land Imager (OLI) multi-wave remote sensing images were obtained for May 2016, the time period during which the snail survey was conducted. Sentinel-1B synthetic aperture radar 
(SAR) images were obtained from the European Space Agency (ESA) Earth Online database (https://earth.esa. int/), and remote sensing image data were obtained from the Sentinel-1B dual-polarized (HV + HH) SAR data for 15 May 2020, corresponding to the time period before the flood, and for 14 July 2020, corresponding to the period of peak flooding. An interferometric wide-swath mode was assigned as the image mode.

\section{Remote sensing image data inversion}

Normalized Difference Vegetation Index (NDVI) data were used as a measure of vegetation coverage in snail habitats, calculated using the following formula [17]:

$$
\mathrm{NDVI}=\frac{\mathrm{NIR}-\mathrm{R}}{\mathrm{NIR}+\mathrm{R}}
$$

wherebNIR indicates the reflectance in near-infrared wavelengths, and $R$ indicates the reflectance in visible red wavelengths. Maximum and minimum NDVI values for snail habitats in the areas around Poyang Lake were calculated based on a dataset of $75 \%$ of snail distribution sites $[18,19]$.
Areas where flood-caused expansion of the water body had occurred were identified using dual-polarized threshold calculations for the time period of the flooding [20]. SAR images were segmented by estimating the small backscattering coefficient thresholds of water on the SAR images [21]. Segmentation results were saved as classification result files, and the classification results were postprocessed. Incorrect extraction images were removed through a human-computer interaction system to yield the final water body data. Sentinel-1B satellite data were processed using the SAR Scape module in the Environment for Visualizing Images (ENVI) software version 5.3 (Exelis Visual Information Solutions, Boulder, CO, USA), which mainly included radiometric calibration, filtering processing, terrain correction and geocoding. Radiometric calibration allows the transformation of image intensity into a backscattering coefficient $\left(\sigma^{0}\right)$, which was calculated using the following formula:

$$
\sigma^{0}=\frac{A^{2}}{K} \sin \theta
$$

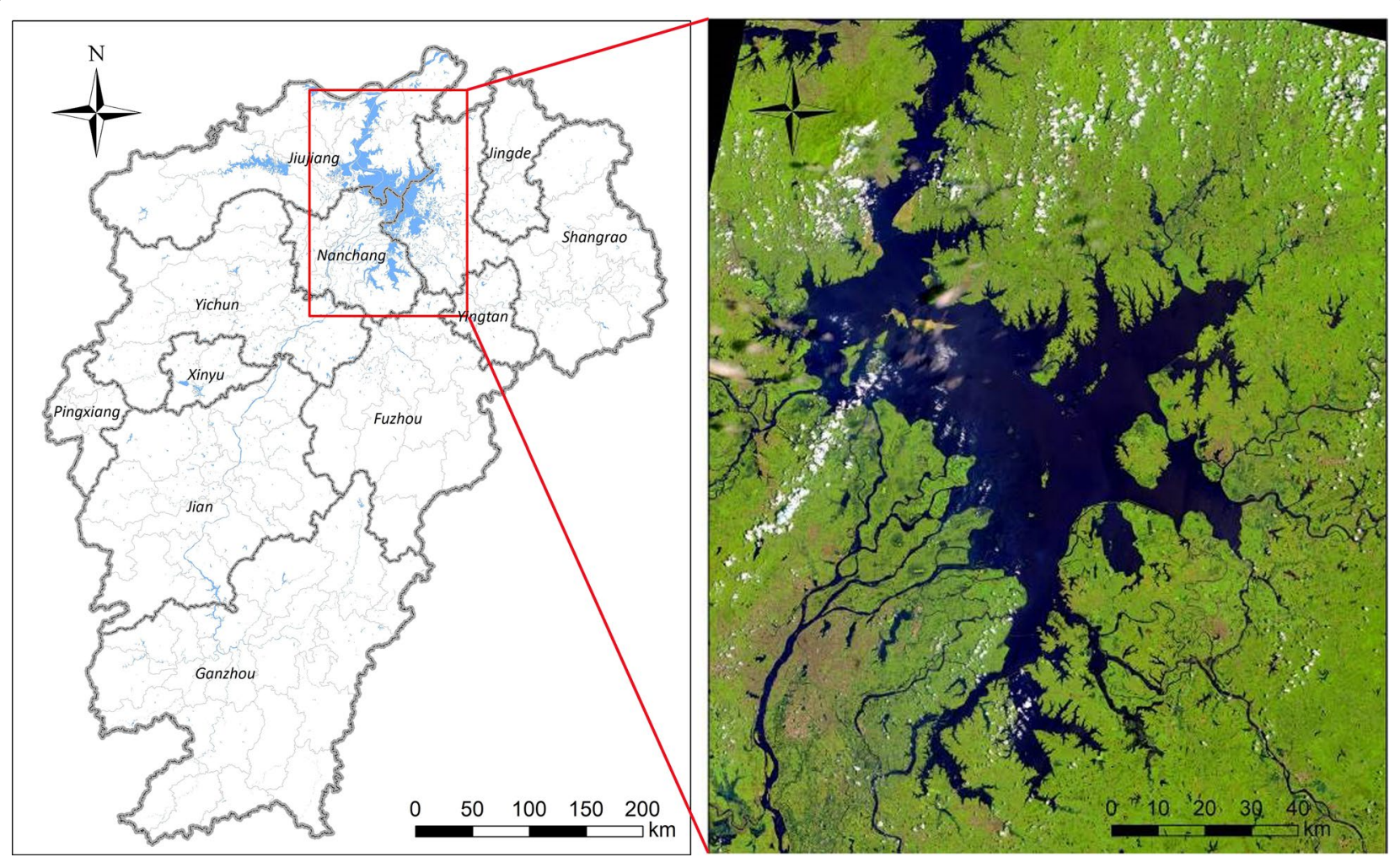

Fig. 1 Geographical location of the study area. Poyang Lake is located in the north of Jiangxi Province and borders the middle and lower reaches of the Yangtze River. The natural geographical features of Poyang Lake are very suitable for snail breeding. A total of 13 counties (districts) in the areas around Poyang Lake, where schistosomiasis is prevalent, were included in this study 
where $\sigma^{0}$ is the backscattering coefficient of each pixel, $A$ is the digital number of original images, $K$ is an absolute calibration factor and $\theta$ is an incident angle.

Because the extraction of the water body data may be interfered with the intrinsic speckle noise in SAR images, a Frost filtering algorithm $(5 \times 5)$ was employed to control the output of a wave filter based on the local statistical characteristics of images [22]. The specific side-view mode of SAR images may lead to the occurrence of foreshortening, layover and shadow in mountains with terrain undulations, which affects the correct analysis of imaging data. Due to the occurrence of terrain undulations in the study area, terrain corrections of SAR images were performed to reduce the error in the water body data caused by geometric characteristics. Geocoding and radiometric calibration of filtered intensity data were also carried out using a digital elevation model (DEM) to generate backscattering coefficient images with dual-polarized $(\mathrm{HV}+\mathrm{HH})$ geographic coordinate systems. The index used for the water body data extraction was calculated based on the backscattering coefficients for $\mathrm{HV}$ and $\mathrm{HH}$ polarizations using the following formula:

$$
\mathrm{R}=\ln (10 \times \mathrm{HV} \times \mathrm{HH})
$$

\section{Risk prediction of schistosomiasis transmission}

Areas neighboring snail habitats which overlapped with flooded areas were extracted from SAR data to determine possible snail distribution zones following flooding [23]. Snail density was estimated from snail habitat-neighboring areas, and the NDVI values corresponding to snail distribution were calculated to predict potential snail spread and associated schistosomiasis transmission risk [24]. A $25 \%$ subset of observed snail breeding sites was selected as a validation dataset [19], and the distribution of snail breeding sites was predicted using model results in ArcGIS software version 10.1. Model predictions corresponding to the validation dataset were extracted, and the predictive accuracy of the model was assessed by identifying snail breeding sites correctly identified by the model [25].

\section{Results}

\section{Distribution of $O$. hupensis snails in the areas} around Poyang Lake

The results of a snail survey carried out in in Jiangxi Province in 2016 found snail habitats to be mainly distributed in 13 marshland and lake counties (cities, districts), including Nanchang, Xinjian, Jinxian, High-tech Zone of Nanchang City, Yongxiu, Gongqingcheng, Lushan, Lianxi, Hukou, Duchang, Poyang, Yugan and Wannian. A total of 1257 habitat settings were identified, with marshlands contributing to $74.94 \%$ of all identified habitat settings. Among the 763 snail habitats identified, 99.48\% were marshland areas. In one marshland area covering $1267.57 \mathrm{~km}^{2}$, snail habitats accounted for $789.01 \mathrm{~km}^{2}$. Among these, along the northern shore of Poyang Lake 12 settings were identified with a density of living snails of $\geq 1$ snail/ $/ 0.1 \mathrm{~m}^{2}$ (7 settings in Lushan, 4 in Hukou and 1 in Yongxiu) and eight settings were identified with $\geq$ $50 \%$ occurrence of frames with living snails (5 settings in Lushan, 2 in Yongxiu and 1 in Hukou) (Table 1).

\section{Environmental identification for suitable snail habitats}

The NDVI values were estimated to range from -1 to 0.61 in the Poyang Lake area based on Landsat 8 remote sensing image data. A total of $75 \%$ of snail distribution sites were randomly sampled from snail habitats identified by field surveys as a training dataset to extract the optimum thresholds of the maximum and minimum value of NDVI at 95\% confidential interval (C)] 0.08 0.59 . The distribution of suitable snail habitats is shown in Fig. 2.

\section{Extraction of flood-cased water body expansion}

Radar echo intensity was determined by brightness in the SAR data. Due to the low echo intensity of water bodies and high echo intensity of the corresponding land areas, water body areas in SAR images appeared as dark or black and the land areas as grayish white or dark gray. Pre-processed SAR images from Sentinel-1B satellite images for the time period before and after flooding are shown in Fig. 3. The speckle noise was effectively inhibited, and a more obvious water-land boundary was seen on original radar images in which the water and land were well differentiated and the water profile was more distinct.

Figure 4 shows a histogram of pre-processed SAR image scattering values before and after flooding. There are two apparent peaks in the histograms in the images presented in Fig. 4, with segmented SAR image thresholds ranging from $-25.5 \mathrm{~dB}$ (before flooding) to -24 $\mathrm{dB}$ (after flooding) based on visual interpretation.

Segmentation results were saved as classification results and transformed to a vector file. Following postclassification data processing, incorrect extraction images were removed through a human-computer interaction to generate a final water body dataset for the Poyang Lake area for the time periods of May 15 and July 14. 


\section{Changes in water body areas before and after flooding}

The distribution of water bodies in areas around Poyang Lake was compared by overlapping imaging data before and after flooding. The blue areas in Fig. 5 indicate the distribution of water bodies before the flood, and red areas describe the expansion of water bodies during flooding. Examination of the main body of Poyang Lake and neighboring water areas from Sentinel-1B SAR images showed that approximately $2207 \mathrm{~km}^{2}$ was covered by water on May 15 and that $4403 \mathrm{~km}^{2}$ was covered by water on July 14 , an increase of $2196 \mathrm{~km}^{2}$ compared to May and an increase of $25.4 \%$ compared to the historical mean level during the same period $\left(3510 \mathrm{~km}^{2}\right)$. Taken as a whole, the area covered by water expanded by approximately $99.5 \%$ after flooding relative to the areas covered by water before flooding, with the increase occurring primarily in Xinjian, Duchang, Poyang, Yongxiu and Yugan (Fig. 5).

\section{Risk Predictions of potential snail diffusion and associated schistosomiasis transmission after the flood}

Data indicating flood-affected water areas were transformed into a binary image of potential snail habitat distribution. Areas of predicted snail diffusion exhibited a patchy, clustered distribution. After submersion of snail habitats following flooding, snail habitats were likely to be in neighboring settings. Snail distribution was predicted to cover an area of approximately $759 \mathrm{~km}^{2}$, mainly occurring in the east of Yongxiu, south of Lushan, southwestern Poyang, southwestern Duchang, northwestern Xinjian and northwestern Yugan. This predicted distribution suggested that areas of possible snail diffusion were predominately concentrated in marshlands around Poyang Lake (Fig. 6).

NDVI values of suitable snail habitats were calculated based on snail density data, with values ranging from 0.15 to 0.35 in high-density snail habitats, from 0.35 to 0.42 in medium-density snail habitats and from $0.08-0.15$ to > 0.42 in low-density snail habitats. NDVI values of floodaffected areas were estimated and the risk of potential snail spread classified accordingly. We found that areas at high risk of snail distribution were predominantly located in northwestern Yongxiu, southwestern Duchang, south of Lushan and southwestern Poyang (Fig. 7). These highrisk areas are also indicative of neighboring areas suitable for snail breeding where snail habitats are likely to emerge following flooding, with the potential for schistosomiasis transmission. Validation of predicted snail habitats was carried out using observational data on snail breeding habitats in order to assess the predictive performance of the model's NDVI value of snail habitats, which ranged from 0.1 to 0.52 using the $25 \%$ validation dataset, with $87 \%$ prediction accuracy, indicating that the NDVI values are a good predictor of snail habitats.

Multiple dikes collapsed following the flooding event in Jiangxi Province. Three sites in Yongxiu and Poyang counties where dikes had collapsed were found to overlap with areas classified as snail distribution risk areas. The sites in Yongxiu and Poyang County where dykes collapsed were predicted to be medium-risk areas of snail distribution, (Fig. 7). The data suggested that snail habitats were likely to emerge at both sites.

\section{Discussion}

Schistosomiasis is a neglected tropical parasitic disease that is strongly associated with ecological and geographic factors. Changes in the natural environments which affect the breeding, reproduction and distribution of intermediate host snails are likely to impact the transmission of schistosomiasis [26, 27]. Previous research has found snail distribution to be closely correlated with vegetation, humidity and temperature, as well as with human and livestock activities, with O. hupensis snails favoring marshlands, ponds and ditches. As the geographical location of schistosomiasis is determined by snail distribution, surveillance of snail habitats is an important component in the national schistosomiasis control program in China.

Flooding frequently occurs along the south and middle and lower reaches of the Yangtze River, areas which are endemic for schistosomiasis. Flooding is considered to be one of the most important natural factors impacting the rebound of schistosomiasis in endemic foci. Periods of flooding impact the geographical expanse, reproduction and growth of $O$. hupensis snails, particularly juvenile snails and snail eggs, which spread via water flow [4, 28,29 ]. Additionally, flood discharge or dike collapse may facilitate the expansion of snail populations into embankments, resulting in the re-emergence of snails in areas where snails had not previously been present [24].

The endemicity of schistosomiasis in China is currently declining, with the country progressing towards elimination [12]. Many challenges to schistosomiasis elimination remain, however, due to natural, biological and social factors [8]. Prevalence of schistosomiasis is high in 11 of the 13 counties (districts) in the Poyang Lake area in Jiangxi Province, with the exception of the high-tech zone of Nanchang City and Wannian County. In 2018, three eggpositive individuals were identified in Yugan County (in total, 8 egg-positive cases in China) and two egg-positive bovines were identified in Duchang County (in total, 2 egg-positive bovines in China) in 2019, suggesting that the risk of schistosomiasis transmission remains in the Poyang Lake area. Interestingly, these areas were identified as high-risk transmission areas in the present study. 


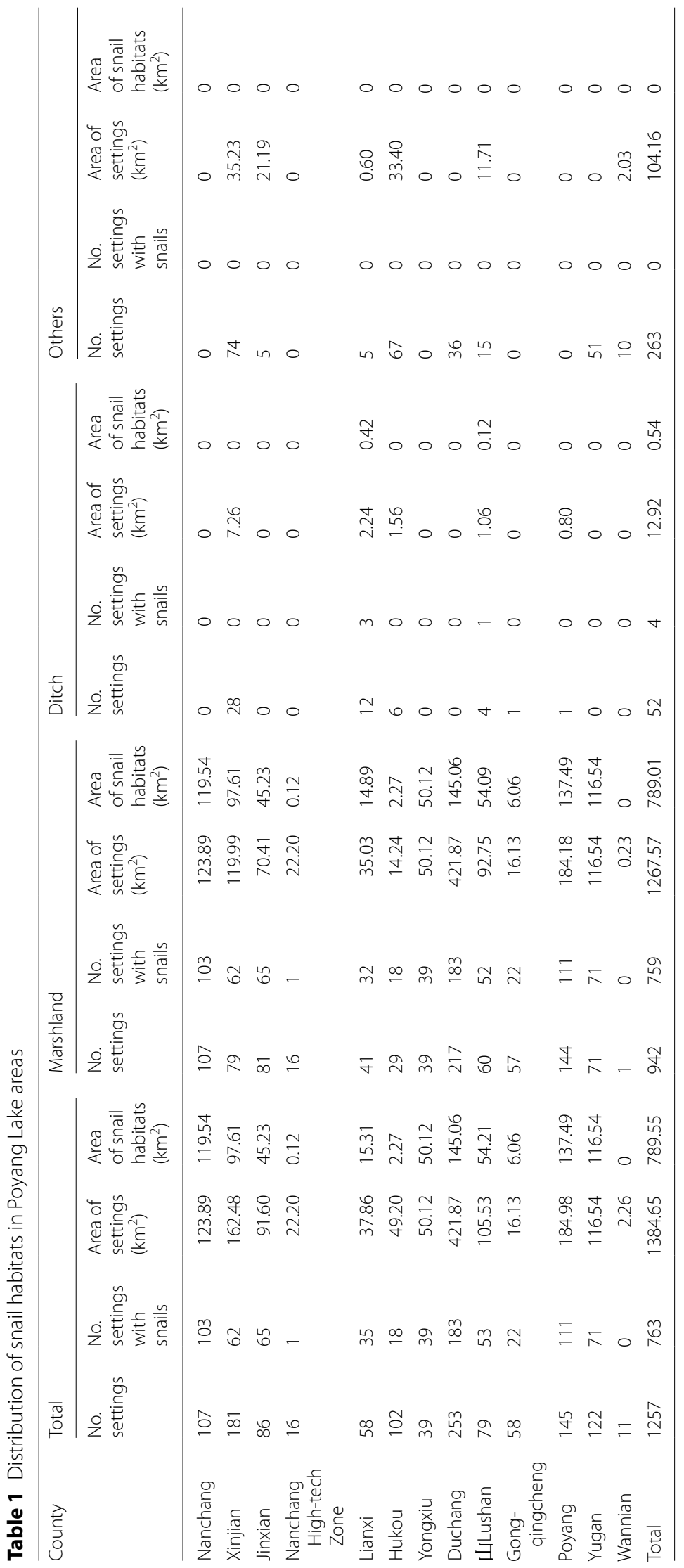




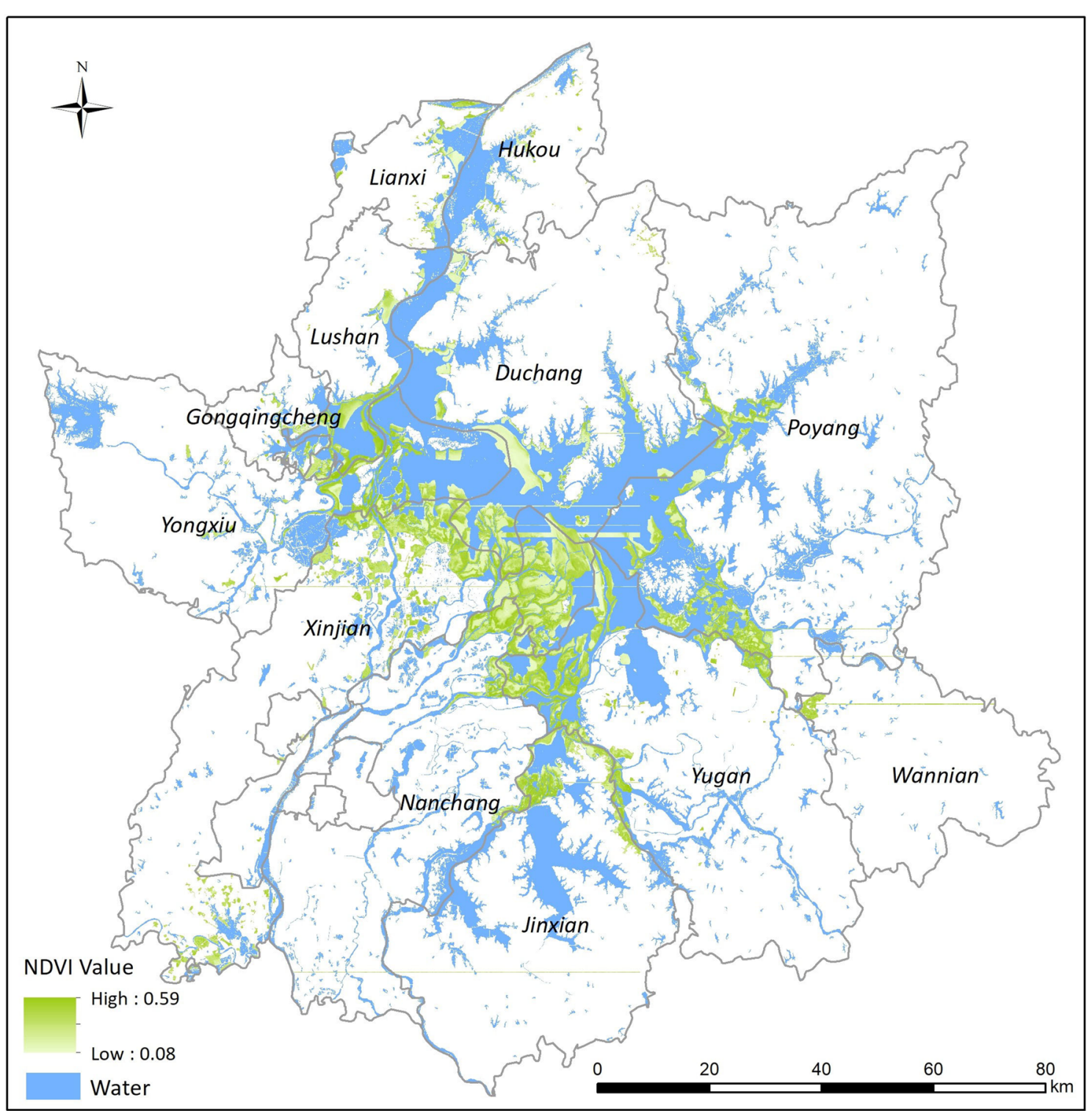

Fig. 2 Distribution of snail habitats in Poyang Lake areas. Snail data were captured from the 2016 snail survey in Jiangxi Province. Normalized Difference Vegetation Index (NDVI) data were used to measure the vegetation coverage in snail habitats, collected from Landsat 8 satellite remote sensing images from the NASA EarthData database

In areas characterized by vast marshlands, multiple grasslands, dense vegetation, difficulty in managing water levels and extensive snail distribution where schistosomiasis was once hyper-endemic and transmission had been controlled or interrupted [9], S. japonicum transmission potential remains due to the distribution of $O$. hupensis snails following flooding. Any relaxing of control interventions would therefore likely result in re-emergence of schistosomiasis infection.
Remote sensing image data have been widely employed for the surveillance of schistosomiasis and the habitats of the intermediate host snails [24, 30-33]. Satellite-based remote sensing collects ecological and geographical data, such as land coverage, vegetation, soil type, surface moisture and rainfall, which may be used to monitor environmental changes, thereby enabling assessment of the suitability of snail breeding habitats to have association potential for schistosomiasis transmission [25, 34-36]. 
a

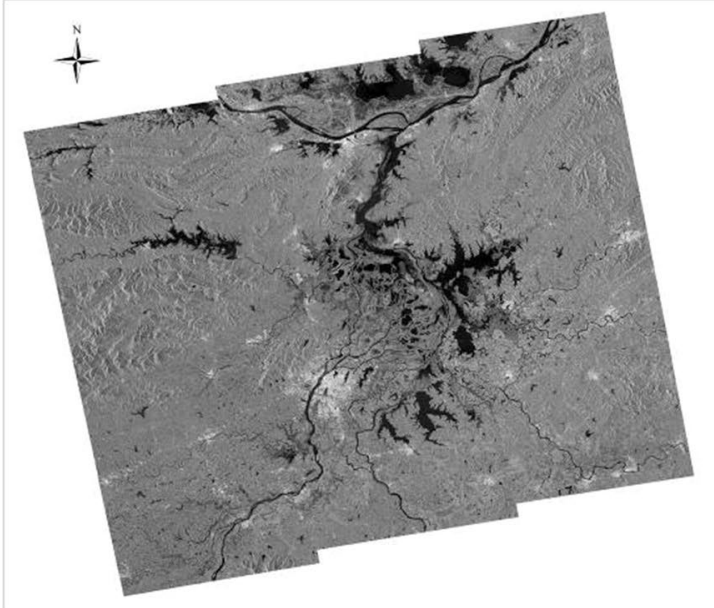

b

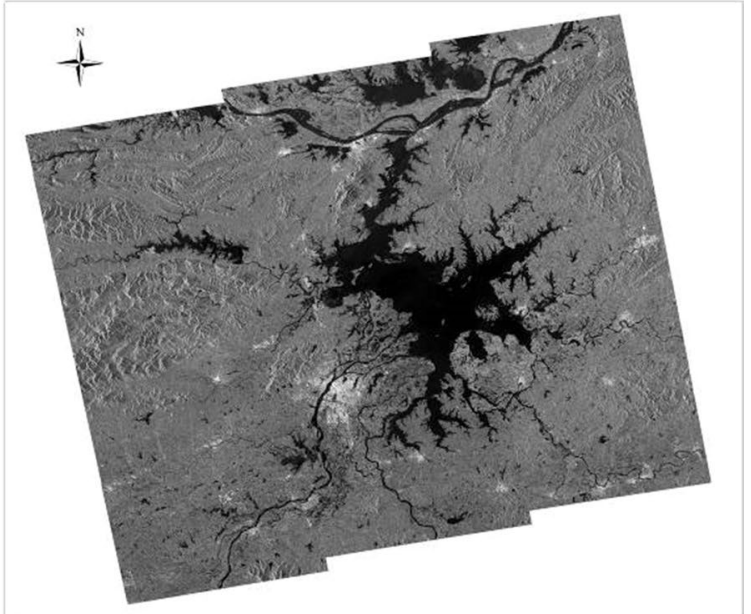

Fig. 3 Waterbody extraction from remote sensing image data in Poyang Lake areas. Image data were collected from ESA Earth Online database of Sentinel-1B dual-polarized (HV + HH) SAR data on 15 May 2020, before the flood (a), and on 14 July 2020, during the period of the flood peak (b)
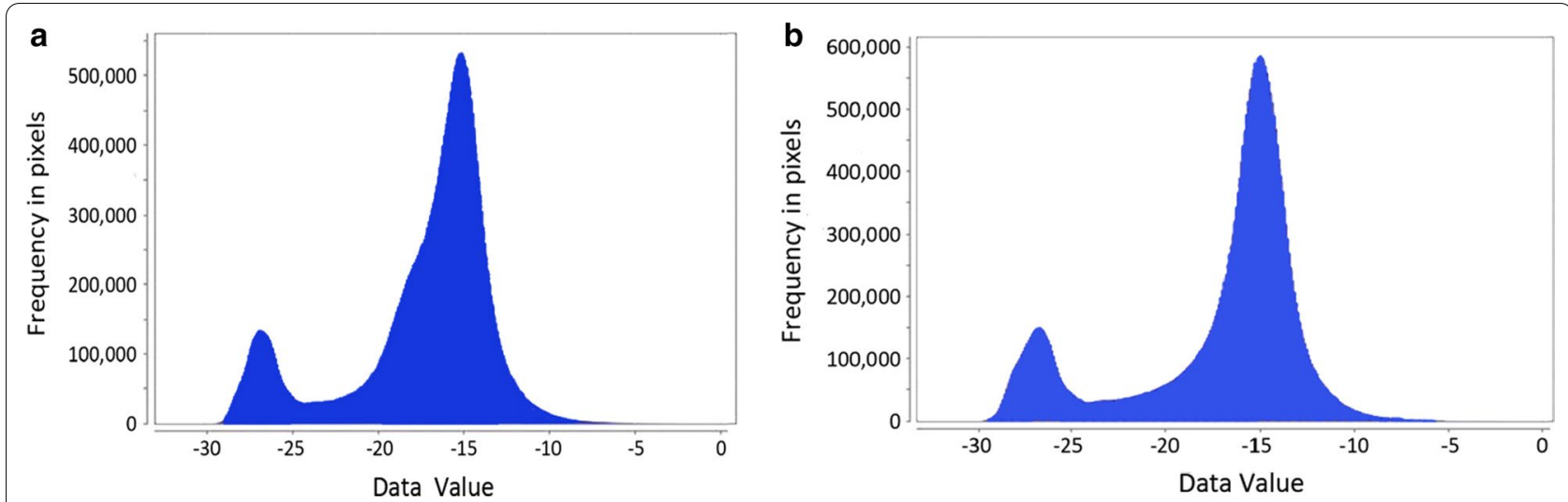

Fig. 4 The histogram of scattering values of SAR radar images for waterbody extractions. a An image captured on 15 May 2020, b an image captured on 14 July 2020. There are two apparent peaks in the histograms of the images, and the thresholds for segmented SAR images were -25.5 and $-24 \mathrm{~dB}$ before and after flooding, respectively

Some limitations are inherent in data of this type, however, such as a short wavelength and potential effects of cloud amount and severe weather. Most notably, during flooding continuous cloudy and rainy conditions may lead to failure in the accurate acquisition of image data in flood-affected areas. Radar images, characterized by full-time and full-weather, high-coverage, high-resolution observations and high revisit rate, are not affected by meteorological conditions or light levels and have been widely employed in the fields of disaster monitoring, agriculture and oceanography [37-42].
In the current study, the distribution of snail habitats was estimated using Landsat 8 satellite remote sensing image data, and areas where water body overlapped before and after flooding were identified using Sentinel-1B dual-polarized image data. The total water body area was estimated to have expanded by approximately 99.5\% in the Poyang Lake region after flooding relative to the water body area before flooding. Snail habitats are likely to emerge in flood-affected areas after flooding has receded. All of these regions were found to be adjacent to, or connected with, original snail habitats, 


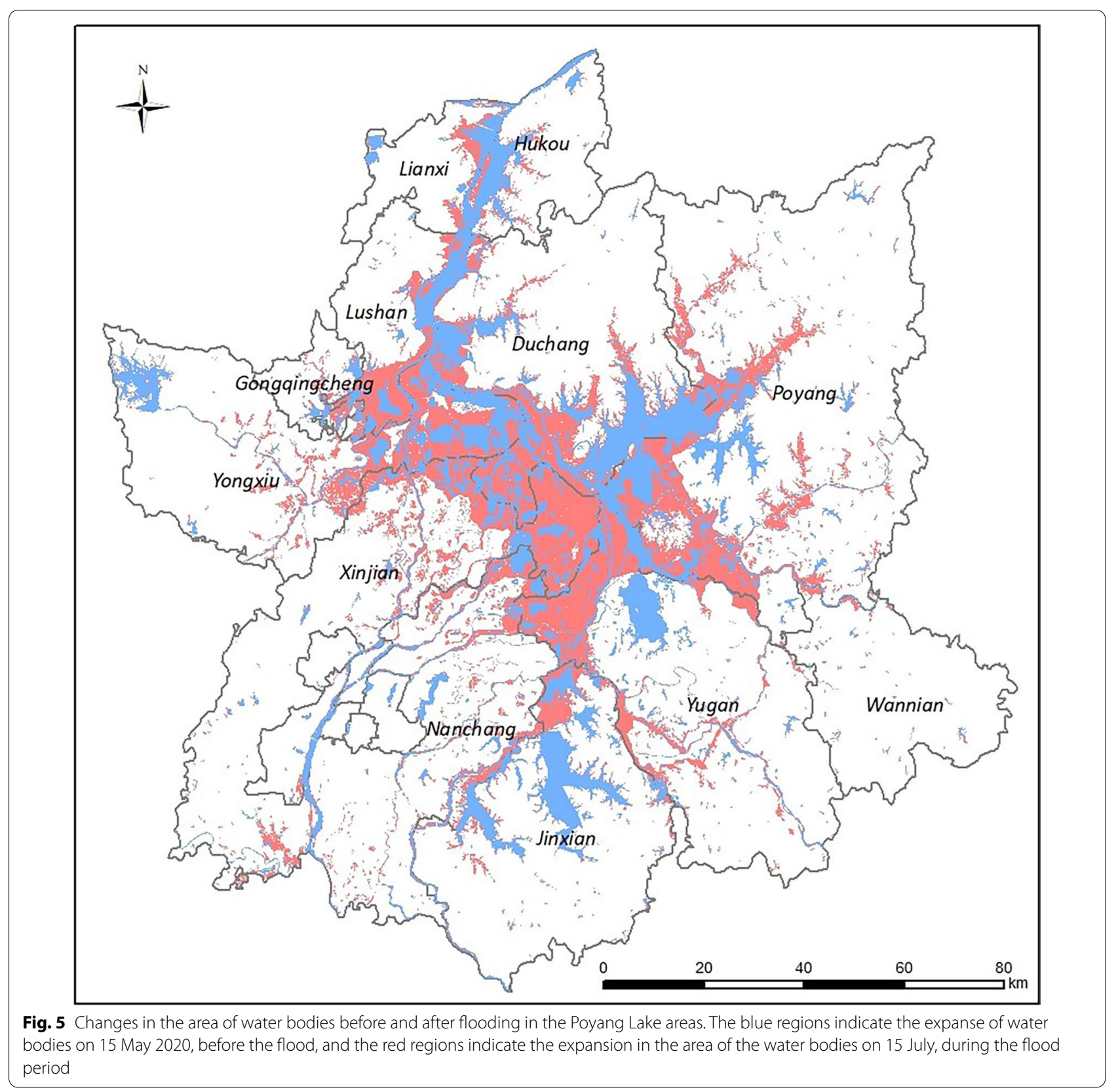

predominantly distributed to the southwest and northwest of Poyang Lake. Snail distribution was predicted to mainly occur in the counties of Yongxiu, Lushan, Poyang, Duchang and Yygan and in Xinjian District. Based on these data, it can be predicted that multiple regions at high risk of schistosomiasis transmission are located in the counties of Yongxiu, Duchang, Lushan and Poyang. The classification of potential snail habitats is consistent with the spatial distribution of schistosomiasis transmission risk in the Poyang Lake regions based on schistosomiasis case reports [9]. 


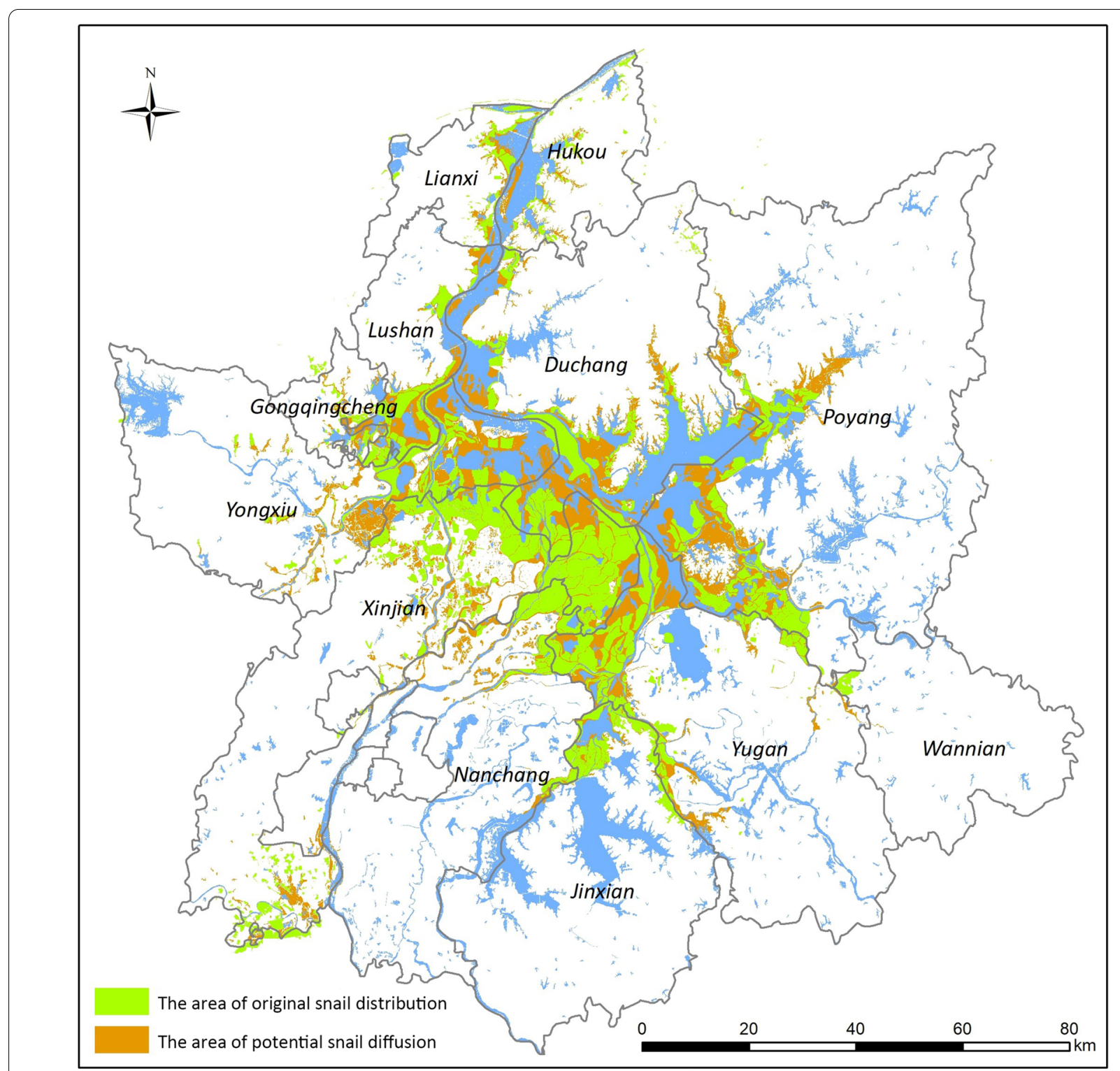

Fig. 6 Prediction of snail habitats based on flood-affected settings. Snail spread was predicted to possibly cover an area of approximately $759 \mathrm{~km}^{2}$ and to mainly ocuur east of Yongxiu, south of Lushan, southwestern Poyang, southwestern Duchang, northwestern Xinjian and northwestern Yugan

\section{Conclusion}

Remote sensing techniques were found to be an effective quantitative tool for the rapid assessment of snail distribution, providing insights into schistosomiasis risk and thereby providing valuable information for control programs. It is recommended that monitoring of $O$. hupensis and epidemiological surveys of $S$. japonicum infections should be conducted by schistosomiasis control institutions in the coming 2-3 years, with the aim to prevent the spreading of snail populations and to reduce the risk of transmission of schistosomiasis. 


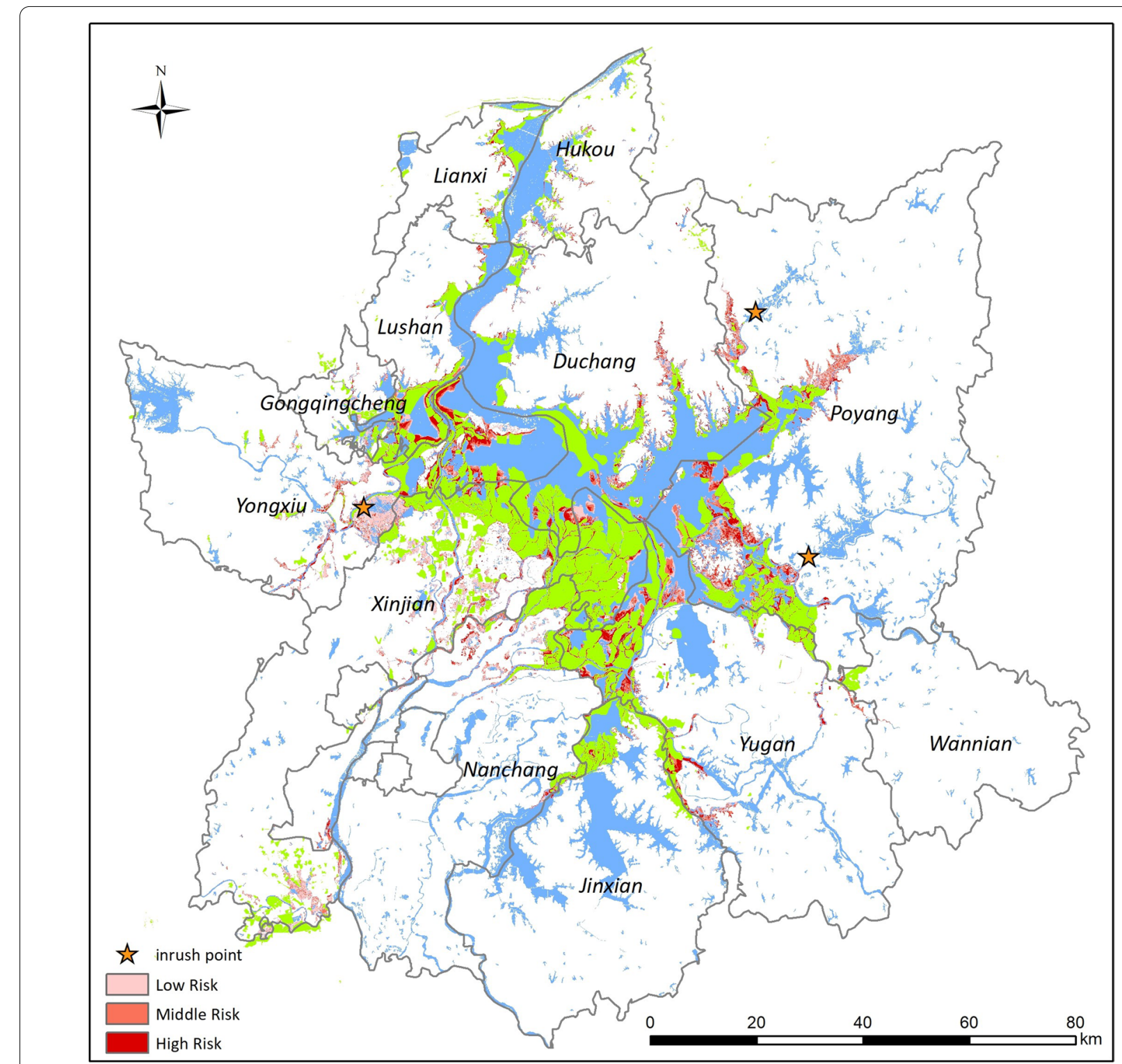

Fig. 7 Risk classification of spread of Oncomelania hupensis. The NDVI values of suitable snail habitats were calculated based on snail density data, and the risk was classified as high-density, medium-density and low-density snail habitats with reference to the NDIV values

\section{Abbreviations}

DEM: Digital elevation model; ENVI: Environment for visualizing images; LAMP: Loop-mediated Isothermal Amplification; NDVI: Normalized Difference Vegetation Index; OLI: Operational land imager; SAR: Synthetic aperture radar.

\section{Acknowledgements}

We are very grateful to all workers in the Jiangxi Institute of Parasitic Diseases for their guidance and support during the field work. We also thank the staff of the Schistosomiasis Department in the National Institute of Parasitic Diseases, Chinese Center for Diseases Control and Prevention for their assistance in analyzing the interpreting the data.

\section{Authors' contributions}

SX and SZL designed the study. ZC and DDL coordinated and carried out the field work. JBX, XYW,LIZ, YWH, JX and SX analyzed and interpreted the data and wrote the initial manuscript. SX and SZL participated in the coordination and revised the manuscript. All authors read and approved the final manuscript.

\section{Funding}

Science and Technology research project of Shanghai Municipal Health Commission (Nos. 20194Y0359, 20174Y0188), the Special Foundation of Basic Science and Technology. Resources Survey of Ministry of Science and Technology of China (No.2017FY101203). The High Resolution Remote Sensing Monitoring Project (No. 10-Y30B11-9001-14/16).

\section{Availability of data and materials}

The datasets analyzed during the present study are available from the corresponding authors upon reasonable request. 
Ethics approval and consent to participate

This study does not involve ethic issues.

\section{Consent for publication}

Not applicable.

\section{Competing interests}

The authors declare that they have no competing interests.

\section{Author details}

${ }^{1}$ National Institute of Parasitic Diseases, Chinese Center for Diseases Control and Prevention, Chinese Center for Tropical Diseases Research, Shanghai 200025, People's Republic of China. ${ }^{2}$ WHO Collaborating Centre for Tropical Diseases, Shanghai 200025, People's Republic of China. ${ }^{3}$ National Center for International Research on Tropical Diseases, Ministry of Science and Technology, Shanghai 200025, People's Republic of China. ${ }^{4}$ Key Laboratory of Parasite and Vector Biology, Ministry of Health, Shanghai 200025, People's Republic of China. ${ }^{5}$ School of Global Health, Chinese Center for Tropical Diseases Research, Shanghai Jiao Tong University School of Medicine, Shanghai 200025, People's Republic of China. ${ }^{6}$ Jiangxi Institute of Parasitic Diseases, Nanchang 330046, Jiangxi, People's Republic of China. ${ }^{7}$ Jiangxi Key Laboratory of Schistosomiasis Prevention and Control, Nanchang 330046, Jiangxi, People's Republic of China.

Received: 12 October 2020 Accepted: 1 January 2021

Published online: 22 February 2021

\section{References}

1. Zhou X-N, Wang L-Y, Chen M-G, Wu X-H, Jiang Q-W, Chen X-Y, et al. The public health significance and control of schistosomiasis in China-then and now. Acta Trop. 2005;96(2-3):97-105.

2. Li S-Z, Zheng H, Abe EM, Yang K, Bergquist R, Qian Y-J, et al. Reduction patterns of acute schistosomiasis in the People's Republic of China. PLoS Negl Trop Dis. 2014;8(5):e2849.

3. Wang L, Utzinger J, Zhou X-N. Schistosomiasis control: experiences and lessons from China. Lancet. 2008;372(9652):1793-5.

4. Yang Y, Gao J, Cheng W, Pan X, Yang Y, Chen Y, et al. Three Gorges Dam: polynomial regression modeling of water level and the density of schistosome-transmitting snails Oncomelania hupensis. Parasites Vectors. 2018;11(1):1-7.

5. Hu F, Li Q-Y, Dai X-F, Li Z-J, Lv S-B, Lu C-F, et al. Impact of continuous low water stage on the breeding environment of Oncomelania hupensis: a case study of Poyang Lake area in China. Infect Dis Poverty. 2020;9(1):1-11.

6. Yuan $Y, X u X-J$, Dong H-F, Jiang M-S, Zhu H-G. Transmission control of schistosomiasis japonica: implementation and evaluation of different snail control interventions. Acta Trop. 2005;96(2-3):191-7.S

7. Zhou X. Implementation of precision control to achieve the goal of schistosomiasis elimination in China. Chin J Schistosomiasis Control. 2016;1:1-4.

8. Wang J-L, Li T-T, Huang S-Y, Cong W, Zhu X-Q. Major parasitic diseases of poverty in mainland China: perspectives for better control. Infect Dis Poverty. 2016;5(1):67.

9. Xia C, Hu Y, Ward MP, Lynn H, Li S, Zhang J, et al. Identification of high-risk habitats of Oncomelania hupensis, the intermediate host of schistosoma japonium in the Poyang Lake region, China: A spatial and ecological analysis. PLoS Negl Trop Dis. 2019;13(6):e0007386.

10. Chen $\mathrm{H}$, Lin D. The prevalence and control of schistosomiasis in Poyang Lake region, China. Parasitol Int. 2004;53(2):115-25.

11. Xu Y, Zhong Y, Xu L, Yang W. Research on spatial-temporal characteristics and driving forces of rural settlements in Jiangxi Province. J Ecol Rural Environ. 2018;34(6):504-11.

12. Zhang L-J, Dai S-M, Xue J-B, Li Y-L, Lv S, Xu J, et al. The epidemiological status of schistosomiasis in PR China after the World Bank Loan Project, 2002-2017. Acta Trop. 2019;195:135-41.

13. Pennance T, Ame SM, Amour AK, Suleiman KR, Allan F, Rollinson D, et al. Occurrence of Schistosoma bovis on Pemba Island, Zanzibar: implications for urogenital schistosomiasis transmission monitoring. Parasitology. 2018;145(13):1727-31.
14. Qin Z-Q, Xu J, Feng T, Lv S, Qian Y-J, Zhang L-J, et al. Field evaluation of a loop-mediated isothermal amplification (LAMP) platform for the detection of Schistosoma japonicum infection in Oncomelania hupensis snails. Trop Med Infect Dis. 2018;3(4):124.

15. Mori Y, Notomi T. Loop-mediated isothermal amplification (LAMP): a rapid, accurate, and cost-effective diagnostic method for infectious diseases. J Infect Chemother. 2009;15(2):62-9.

16. Zhou X-N, Xu J, Chen H-G, Wang T-P, Huang X-B, Lin D-D, et al. Tools to support policy decisions related to treatment strategies and surveillance of Schistosomiasis japonica towards elimination. PLoS Neglected Trop Dis. 2011;5(12):e1408.

17. Walz Y, Wegmann M, Leutner B, Dech S, Vounatsou P, N'Goran EK, et al. Use of an ecologically relevant modelling approach to improve remote sensing-based schistosomiasis risk profiling. Geospat Health. 2015;10(2):398.

18. Storkey A. When training and test sets are different: characterizing learning transfer. In: Sugiyama C, Schwaighofer L, editors. Dataset shift in machine learning. Cambridge: MIT Press; 2009. p. 3-28.

19. Liu H, Cocea M. Semi-random partitioning of data into training and test sets in granular computing context. Granul Comput. 2017;2(4):357-86.

20. Hong R, Guo X, Tu J, Zhang R. The water extraction and flood season changes detection of Poyang Lake based on dual polarized Sentinel-1A image data. Geomatics Sci Technol. 2018;6(04):298-308.

21. Manavalan R. SAR image analysis techniques for flood area mappingliterature survey. Earth Sci Inf. 2017;10(1):1-14.

22. Sun Z, Zhang Z, Chen Y, Liu S, Song Y. Frost filtering algorithm of SAR images with adaptive windowing and adaptive tuning factor. IEEE Geosci Remote Sens Lett. 2019;17(6):1097-101.

23. Walz Y, Wegmann M, Dech S, Raso G, Utzinger J. Risk profiling of schistosomiasis using remote sensing: approaches, challenges and outlook. Parasites Vectors. 2015;8(1):163.

24. Shi Y, Qiu J, Li R, Shen Q, Huang D. Identification of potential high-risk habitats within the transmission reach of Oncomelania hupensis after floods based on SAR techniques in a plane region in china. Int J Environ Res Public Health. 2017;14(9):986.

25. Walz Y, Wegmann M, Dech S, Vounatsou P, Poda J-N, N'Goran EK, et al. Modeling and validation of environmental suitability for schistosomiasis transmission using remote sensing. PLoS Neglected Trop Dis. 2015;9(11):e0004217.

26. Li Z-J, Ge J, Dai J-R, Wen L-Y, Lin D-D, Madsen H, et al. Biology and control of snail intermediate host of Schistosoma japonicum in the People's Republic of China. Adv Parasitol. 2016:92:197-236.

27. Kalinda C, Chimbari M, Mukaratirwa S. Implications of changing temperatures on the growth, fecundity and survival of intermediate host snails of schistosomiasis: a systematic review. Int J Environ Res Public Health. 2017;14(1):80.

28. Paweł-AlexandroWicz W. Terrestrial snails in flood deposits of the Beskid Mały range (Carpathians, southern Poland). Folia Malacol. 2019;27(4):293-306.

29. Yang Y, Zheng S-B, Yang Y, Cheng W-T, Pan X, Dai Q-Q, et al. The three gorges dam: does the flooding time determine the distribution of schistosome-transmitting snails in the middle and lower reaches of the Yangtze River, China? Int J Environ Res Public Health. 2018;15(7):1304.

30. Zhang Z, Bergquist R, Chen D, Yao B, Wang Z, Gao J, et al. Identification of parasite-host habitats in Anxiang county, Hunan Province, China based on multi-temporal China-Brazil earth resources satellite (CBERS) images. PLoS One. 2013:8(7):e69447.

31. Martins-Bedê FT, Dutra LV, Freitas CC, Guimarães RJ, Amaral RS, Drummond SC, et al. Schistosomiasis risk mapping in the state of Minas Gerais, Brazil, using a decision tree approach, remote sensing data and sociological indicators. Mem Inst Oswaldo Cruz. 2010;105(4):541-8.

32. Wrable M, Kulinkina AV, Liss A, Koch M, Cruz MS, Biritwum N-K, et al. The use of remotely sensed environmental parameters for spatial and temporal schistosomiasis prediction across climate zones in Ghana. Environ Monit Assess. 2019;191(2):301.

33. Simoonga C, Utzinger J, Brooker S, Vounatsou P, Appleton C, Stensgaard A-S, et al. Remote sensing, geographical information system and spatial analysis for schistosomiasis epidemiology and ecology in Africa. Parasitology. 2009;136(13):1683.

34. Kristensen T, Malone J, McCarroll J. Use of satellite remote sensing and geographic information systems to model the distribution and 
abundance of snail intermediate hosts in Africa: a preliminary model for Biomphalaria pfeifferi in Ethiopia. Acta Trop. 2001;79(1):73-8.

35. Meyer EL, Matzke NJ, Williams SJ. Remote sensing of intertidal habitats predicts West Indian topsnail population expansion but reveals scaledependent bias. J Coastal Conserv. 2015;19(2):107-18.

36. Freitas C, Guimarães R, Dutra L, Martins F, Gouvea E, Santos R, et al: Remote sensing and geographic information systems for the study of schistosomiasis in the state of Minas Gerais, Brazil. In: 2006 IEEE International Symposium on Geoscience and Remote Sensing, 31 July-4 Aug 2006, Denver, CO. p. 2436-9.

37. Schulz-Stellenfleth J, König T, Lehner S. An empirical approach for the retrieval of integral ocean wave parameters from synthetic aperture radar data. J Geophys Res. 2007;112:C3.

38. Kudryavtsev V, Myasoedov A, Chapron B, Johannessen JA, Collard F. Imag ing mesoscale upper ocean dynamics using synthetic aperture radar and optical data. J Geophys Res. 2012;117:C4.

39. Zhang K, Huang J, Mansaray LR, Guo Q, Wang X. Developing a subswath-based wind speed retrieval model for Sentinel-1 VH-polarized SAR data over the ocean surface. IEEE Trans Geosci Remote Sens. 2018:57(3):1561-72.
40. Dingle Robertson L, Davidson A, McNairn H, Hosseini M, Mitchell S, De Abelleyra D, et al. Synthetic Aperture Radar (SAR) image processing for operational space-based agriculture mapping. Int J Remote Sens. 2020;41(18):7112-44.

41. Baghdadi N, Cerdan O, Zribi M, Auzet V, Darboux F, El Hajj M, et al. Operational performance of current synthetic aperture radar sensors in mapping soil surface characteristics in agricultural environments: application to hydrological and erosion modelling. Hydrol Process. 2008;22(1):9-20.

42. Sumantyo JTS. Development of circularly polarized synthetic aperture radar onboard microsatellite for earth diagnosis. In: 2011 IEEE International Geoscience and Remote Sensing Symposium, 01-05 Aug 2011 Sendai, Japan. p. 929-32.

\section{Publisher's Note}

Springer Nature remains neutral with regard to jurisdictional claims in published maps and institutional affiliations.
Ready to submit your research? Choose BMC and benefit from:

- fast, convenient online submission

- thorough peer review by experienced researchers in your field

- rapid publication on acceptance

- support for research data, including large and complex data types

- gold Open Access which fosters wider collaboration and increased citations

- maximum visibility for your research: over $100 \mathrm{M}$ website views per year

At BMC, research is always in progress.

Learn more biomedcentral.com/submissions 